\title{
Concurrent Chemoradiation with Weekly Cisplatin for the Treatment of Head and Neck Cancers: an Institutional Study on Acute Toxicity and Response to Treatment
}

\author{
Saptarshi Ghosh*, Pamidimukkala Brahmananda Rao, P Ravindra Kumar, \\ Surendra Manam
}

\begin{abstract}
Background: Concurrent chemoradiation with three weekly high dose cisplatin is the non-surgical standard of care for the treatment of locally advanced head and neck cancers. Although this treatment regime is efficacious, it has high acute toxicity, which leads not only to increased treatment cost, but also to increased overall treatment time. Hence, the current study was undertaken to evaluate the acute toxicity and tumor response in head and neck cancer patients treated with concurrent chemoradiation using $40 \mathrm{mg} / \mathrm{m}^{2}$ weekly cisplatin, which has been our institutional practice. Materials and Methods: This single institution retrospective study included data for 287 head and neck cancer patients treated with concurrent chemoradiation from 2012 to 2014. Results: The mean age of the patients was 48.8 years. The most common site of involvement was oral cavity. Most of the study patients presented with advanced stage disease. The mean overall treatment time was 56.9 days. Some $67.2 \%$ had overall complete response to treatment as documented till 90 days from the start of treatment. According to the Radiation Therapy Oncology Group (RTOG) acute radiation morbidity scoring criteria, mucositis was seen in $95.1 \%$ of the patients. Dermatitis and emesis were observed in $81.9 \%$ and $98.6 \%$, respectively. Regarding haematological toxicity, $\mathbf{4 8 . 8 \%}$ and $\mathbf{2 9 . 6 \%}$ suffered from anaemia and leukopenia, respectively, during treatment. Acute kidney injury was assessed using the Common Terminology Criteria for Adverse Events (CTCAE), and was found in $\mathbf{1 8 . 8 \%}$ of the patients. Conclusions: Concurrent chemoradiotherapy with weekly cisplatin is an effective treatment regime for head and neck cancers with reasonable toxicity which can be used in developing countries, where cost of treatment is so important.
\end{abstract}

Keywords: Cobcurrent chemoradiation - RTOG - CTCAE - developing countries - efficacy

Asian Pac J Cancer Prev, 16 (16), 7331-7335

\section{Introduction}

Overall $57.5 \%$ of the head and neck cancers (excluding oesophageal cancers) worldwide occur in Asia, especially in India (Chaturvedi, 2009). The reflected burden of head and neck cancers (HNCA) in India is actually much less than the actual burden, and has been compared to the tip of the iceberg (Mishra et al., 2014). Majority of the patients with HNCA present in Stage IV disease in India (Pandey et al., 2014).

Organ preservation approach with chemoradiotherapy is currently the standard of care for the management of HNCA (Lasrado et al., 2014). Based on the metaanalysis of the MACH-NC collaborative group, which demonstrated a $6.5 \%$ absolute survival advantage at 5 years in HNCA with concurrent chemoradiation, platinum based concurrent chemoradiation has become the nonsurgical standard of care in the treatment of HNCA(Pignon et al., 2007). Although 3 weekly high dose cisplatin is the current chemotherapy of choice while given concurrently with radiation (Pignon et al., 2000, 2005, 2007), there is still no uniform consensus on it due to the wide variation in various study designs and due to the different ways of combining chemotherapy with radiation (Browman et al., 2001; Baykara et al., 2013). Further, the 3 weekly high dose cisplatin based chemoradiation regime has been shown to have considerable haematological toxicity and is non-compliant in one-third of the patients (Brizel et al., 2006). The situation is further complex in developing countries like India, where there are limited resources and the patients need intensive inpatient care. Hence, moderate doses of weekly cisplatin has been advocated as concurrent chemoradiation (Dimri et al., 2013).

The current study aims at finding out the efficacy and acute toxicity of concurrent chemoradiation with moderate dose cisplatin in Indian setting.

\section{Materials and Methods}

\section{Study design}

This is a single institutional retrospective study done with the data available from the computer and clinical 
case sheets of the patients with squamous cell carcinoma of the head and neck who were treated in the Department of Radiotherapy in a South Indian institute from January 2012 to December 2014. Previously untreated patients with non-metastatic HNCA (excluding cancers of the esophagus, nasopharynx and paranasal sinuses) who were treated with $40 \mathrm{mg} / \mathrm{m}^{2}$ cisplatin based concurrent chemoradiation were only included in the study. Patients treated with neoadjuvant or adjuvant chemotherapy were excluded from the study. Patients treated with any other chemotherapeutic agents or with any other dosage regime of cisplatin were also excluded from the study. All patients who completed their treatment were only included in the present study. A total of 287 patients were found to be satisfying the inclusion criteria of the study.

\section{Radiotherapy}

All patients were treated with conventional radiotherapy with $6 \mathrm{MV}$ photons with a linear accelerator after immobilization with thermoplastic mask. All patients were treated with conventional fractionation. The gross tumor volume was treated to a dose of 66 or $70 \mathrm{~Gy}$ in 33- 35 fractions. The first phase 46 Gy was delivered in 23 fractions to the mid-plane with pair opposing lateral fields. The lower neck whenever indicated, was treated with a matched low anterior neck field upto a dose of 50 Gy in 25 fractions using a half beam block, normalized at 2-3 cms of depth. In the second phase, shrinking field off-cord technique was used to deliver the radiation dose to the primary tumor site along with the nodal sites with a 2-3 cms margin upto a dose of 66 or $70 \mathrm{~Gy}$.

\section{Chemotherapy}

$40 \mathrm{mg} / \mathrm{m}^{2}$ weekly cisplatin was administered intravenously during the course of radiation. Prechemotherapy hydration was given with $1000 \mathrm{ml}$ normal saline and $500 \mathrm{ml}$ of dextrose normal saline. Antiemetic premedication was given with $8 \mathrm{mg}$ of dexamethasone and $8 \mathrm{mg}$ of ondansetron. Cisplatin was delivered along with $500 \mathrm{ml}$ of normal saline over 3 hours. Post-chemotherapy hydration was given with $1000 \mathrm{ml}$ of normal saline and $500 \mathrm{ml}$ of ringer lactate along with $10 \mathrm{ml}$ of magnesium sulphate. Also $100 \mathrm{ml}$ of $20 \%$ mannitol is given postchemotherapy to ensure forced diuresis. On the day of the chemotherapy, radiation was delivered within an hour of cisplatin administration. Post-chemotherapy antiemetic prophylaxis was given with pantoprazole, domperidone and ondansetron for the next five days. Chemotherapy administration was postponed if the haemoglobin level was less than $9 \mathrm{gm} / \mathrm{dl}$ or total leukocyte count was less than $2500 \mathrm{~mm}-3$ or platelet count was less than 75,000 mm-3 or serum creatinine was more than $1.5 \mathrm{mg} \%$, till recovery. Dose modifications were not done in any patient.

\section{Patient evaluation}

All the study patients were evaluated weekly during the course of chemoradiotherapy for assessing the toxicity of the treatment. After completion of chemoradiation, all patients were followed up after every 4 weeks for the next two months to assess the acute toxicity till the day 90 from the commencement of treatment and also to assess the response to the treatment. All acute toxicities were recorded according to the Radiation Therapy Oncology Group (RTOG) guidelines (Cox et al., 1995) apart from the acute kidney injury, which was recorded according to the Common Toxicity Criteria grading system. Disease control was assessed clinically or with direct laryngoscopy whenever indicated till two months from the completion of treatment. The response to treatment were graded as complete response (CR) or partial response (PR) and no response (NR). Response was evaluated for the primary tumor site and the loco-regional lymph nodal sites. An overall response rate was also assessed which included both primary tumor site response as well as regional nodal response.

\section{Statistical analysis}

All data were tabulated in Microsoft Excel and analysed with SPSS (Statistical Package for Social Sciences) software version 20 . The response to treatment was correlated with various prognostic variables by using the Chi-square test. p-value less than 0.05 was taken to be statistically significant.

\section{Results}

During the study period, 287 patients of HNCA satisfied our study criteria. The baseline characteristics of patients, tumors and the treatment variables are depicted in Table $1.58 .2 \%$ of the patients were of age less than or equal to 50 years. $65.9 \%$ of the study patients were males. Cancers of the oral cavity were the most commonly found primary tumors accounting for $36.9 \%$ of the patients, while $31 \%$ of the study patients had primary oropharyngeal cancers. According to the AJCC 7th edition staging, $51.6 \%$ of the patients presented with $\mathrm{T} 3$ primary tumors and $39.4 \%$ patients had N2 nodal disease. Majority of the patients presented with Stage IV disease. There were no patients with Stage I disease and only $7.3 \%$ study patients presented with Stage II disease. A total radiation dose of 66 Gy was delivered in $68.3 \%$ of the study patients, while the rest were administered a dose of $70 \mathrm{~Gy}$. Most of the patients treated in 2014, were treated upto $70 \mathrm{~Gy}$ due to the better tolerance of concurrent chemoradiation over the years. $83.6 \%$ of the study patients received more than 4 cycles of concurrent weekly cisplatin. The mean overall treatment time was 57 days. Only $57.1 \%$ patients completed their overall treatment within 57 days. This prolonged overall treatment time was mostly due to the reluctance of the patients (most of whom were rural) and some due to non-compliance to treatment. 110 patients of the 123 who had overall treatment time more than 57 days, were reluctant to come for daily treatment, while treatment time was prolonged due to treatment non-compliance in only 13 of these 123 patients.

\section{Response rates}

Response to treatment was assessed till two months after the completion of treatment. Complete response in primary tumor site, regional nodal site and overall was seen after treatment completion in $81.2 \%, 77 \%$ and $67.2 \%$ patients respectively. Partial response to treatment 
Concurrent Chemoradiation with Weekly Cisplatin for Head and Neck Cancers: an Institutional Study of Toxicity and Response

in primary site of the tumor, regional nodal site and overall was observed in $17.1 \%, 20.9 \%$ and $28.9 \%$ patients respectively. No overall response was seen in 11 patients

Table 1. Patient, Disease and Treatment Variables in the Study

\begin{tabular}{|c|c|c|}
\hline & $\begin{array}{l}\text { Number of patients } \\
\qquad(\mathrm{n}=287)\end{array}$ & $\begin{array}{l}\text { Percentage } \\
\text { of patients }\end{array}$ \\
\hline \multicolumn{3}{|l|}{ Age } \\
\hline$\leq 50$ years & 167 & 58.2 \\
\hline$>50$ years & 120 & 41.8 \\
\hline \multicolumn{3}{|l|}{ Sex } \\
\hline Male & 189 & 65.9 \\
\hline Female & 98 & 34.1 \\
\hline \multicolumn{3}{|l|}{ Primary tumor site } \\
\hline Oral cavity & 106 & 36.9 \\
\hline Oropharynx & 89 & 31 \\
\hline Hypopharynx & 47 & 16.4 \\
\hline Larynx & 45 & 15.7 \\
\hline \multicolumn{3}{|l|}{ Histopathological Grade } \\
\hline Well Differentiated & 88 & 30.7 \\
\hline Moderately Differentiated & 165 & 57.5 \\
\hline Poorly Differentiated & 34 & 11.8 \\
\hline \multicolumn{3}{|l|}{ T Stage } \\
\hline T 1 & 20 & 7 \\
\hline $\mathrm{T} 2$ & 73 & 25.4 \\
\hline Т 3 & 148 & 51.6 \\
\hline T 4 & 46 & 16 \\
\hline \multicolumn{3}{|l|}{ N Stage } \\
\hline N 0 & 64 & 22.3 \\
\hline $\mathrm{N} 1$ & 67 & 23.3 \\
\hline $\mathrm{N} 2$ & 113 & 39.4 \\
\hline N 3 & 43 & 15 \\
\hline \multicolumn{3}{|l|}{ AJCC Stage } \\
\hline Stage II & 21 & 7.3 \\
\hline Stage III & 99 & 34.5 \\
\hline Stage IV & 167 & 59.4 \\
\hline \multicolumn{3}{|l|}{ RT dose delievered } \\
\hline 66 Gy & 196 & 68.3 \\
\hline 70 Gy & 91 & 31.7 \\
\hline \multicolumn{3}{|c|}{ Number of cycles of Chemotherapy } \\
\hline$\leq 4$ & 47 & 16.4 \\
\hline$>4$ & 240 & 83.6 \\
\hline \multicolumn{3}{|l|}{ Overall treatment time } \\
\hline$\leq 57$ Days & 164 & 57.1 \\
\hline > 57 Days & 123 & 42.9 \\
\hline
\end{tabular}

Table 2. Response rates to treatment

\begin{tabular}{lcc}
\hline $\begin{array}{l}\text { Types of Response } \\
\text { to treatment }\end{array}$ & $\begin{array}{c}\text { Number of } \\
\text { patients }\end{array}$ & $\begin{array}{c}\text { Percentage } \\
\text { of patients }\end{array}$ \\
\hline Primary tumor response & 233 & 81.2 \\
CR & 49 & 17.1 \\
PR & 5 & 1.7 \\
NR & & \\
Regional nodal response & 221 & 77 \\
CR & 60 & 20.9 \\
PR & 6 & 2.1 \\
NR & 193 & 67.2 \\
Overall response & 83 & 28.9 \\
CR & 11 & 3.8 \\
PR & & \\
NR & & \\
\hline CR $=$ Complete response, PR = Partial response, NR = No response
\end{tabular}

Table 3. Acute Toxicity in the Study Patients

\begin{tabular}{|c|c|c|c|}
\hline Acute toxicities & $\begin{array}{l}\text { des } \\
\text { icity }\end{array}$ & $\begin{array}{c}\text { Number } \\
\text { of patients }\end{array}$ & $\begin{array}{l}\text { Percentage } \\
\text { of patients }\end{array}$ \\
\hline \multirow[t]{5}{*}{ Mucositis } & 0 & 14 & 4.9 \\
\hline & I & 32 & 11.1 \\
\hline & II & 104 & 36.2 \\
\hline & III & 97 & 33.8 \\
\hline & IV & 40 & 13.9 \\
\hline \multirow[t]{5}{*}{ Dermatitis } & 0 & 52 & 18.1 \\
\hline & I & 35 & 12.2 \\
\hline & II & 97 & 33.8 \\
\hline & III & 72 & 25.1 \\
\hline & IV & 31 & 10.8 \\
\hline \multirow[t]{4}{*}{ Emesis } & 0 & 4 & 1.4 \\
\hline & I & 192 & 66.9 \\
\hline & II & 72 & 25.1 \\
\hline & III & 19 & 6.6 \\
\hline \multirow[t]{4}{*}{ Anemia } & 0 & 147 & 51.2 \\
\hline & I & 91 & 31.7 \\
\hline & II & 45 & 15.7 \\
\hline & III & 4 & 1.4 \\
\hline \multirow[t]{5}{*}{ Leucopenia } & 0 & 202 & 70.4 \\
\hline & I & 36 & 12.5 \\
\hline & II & 32 & 11.1 \\
\hline & III & 13 & 4.5 \\
\hline & IV & 4 & 1.4 \\
\hline \multirow[t]{3}{*}{ Thrombocytopenia } & 0 & 269 & 93.7 \\
\hline & I & 15 & 5.2 \\
\hline & II & 3 & 1.1 \\
\hline \multirow[t]{3}{*}{ Acute kidney injury (CTCAE) } & 0 & 233 & 81.2 \\
\hline & $\mathrm{I}$ & 49 & 17.1 \\
\hline & II & 5 & 1.7 \\
\hline
\end{tabular}

CTCAE $=$ Common Toxicity Criteria for Adverse Events

(Table 2). On applying Chi-square test, site of primary tumor ( $p$-value $<0.001$ ), stage of disease ( $p$-value $<0.001$ ), total radiation dose delivered ( $p$-value $<0.001$ ) and overall treatment time (p-value 0.023 ) demonstrated statistically significant correlation with the overall tumor response to treatment.

\section{Acute toxicity}

Acute toxicities in the study patients have been depicted in Table 3. Grade II, III and IV mucositis was present in $36.2 \%, 33.8 \%$ and $13.9 \%$ patients respectively. RTOG Grade II, III and IV skin toxicity was seen in 33.8\%, $25.1 \%$ and $10.8 \%$ of the study patients respectively. Apart from four patients, all the study patients had vomiting episodes inspite of the administration of the antiemetics. $51.2 \%, 70.4 \%$ and $93.7 \%$ of the study patients did not have any anemia, leukopenia and thrombocytopenia respectively. In terms of acute kidney injury as graded according to the CTCAE Version $4,17.1 \%$ and $1.7 \%$ patients had Grade I and Grade II toxicity respectively. Majority of the toxicities occurred in between the 3rd week and $7^{\text {th }}$ week of treatment initiation.

\section{Discussion}

The present study reports one of the largest singleinstitutional experience of concurrent weekly cisplatin based chemoradiation in the non-surgical management of HNCA in South India. The aim of this study was to 
address the patient and tumor characteristics in South Indian setting and the post-treatment tumor response rates and acute morbidity associated with concurrent weekly cisplatin based chemoradiotherapy.

The mean age of presentation with HNCA in our study was 48.8 years. This is quite low when compared to western literature (Fan et al., 2012). But similar mean age of presentation has been reported in Indian studies (Gupta et al., 2009; Dimri et al., 2013). The earlier age of presentation in the current study may be attributed to the rampant use of chewable tobacco, smoking and also reverse smoking. There was a relatively higher rate of HNCA in females in the current study when compared to other Indian studies (Dimri et al., 2013), which can be attributed to the higher incidence of reverse smoking and smoking in the study population. The most commonly encountered primary tumors were that of oral cavity (hard palate mostly), which can be again attributed to the practice of reverse smoking in this part of the country and also the habit of chewing tobacco and betelnut. Similar to some other Indian studies (Lasrado et al., 2014), more than $50 \%$ tumors were moderately differentiated. Alike other Indian studies (Gupta et al., 2009; Dimri et al., 2013), T3 tumors were the most common primary tumors. Majority of the study patients presented with AJCC Stage III or IV tumors, which is in concordance with data from other developing countries (Pruegsanusak et al., 2012). Similar to other regional studies (Dimri et al., 2013), 83.6\% patients received more than 4 cycles of weekly cisplatin with concurrent radiation. The mean overall treatment time was higher in the current study when compared to other literature, because most of the present study patients were illiterate and came from rural background, hence were many a times reluctant to come for treatment even after repeated counselling. Very few patients were actually delayed treatment due to non-compliance.

A meta-analysis (Pignon et al., 2009) with a total of 87 trials and 16,485 patients demonstrated a $4.5 \%$ absolute benefit of chemotherapy at 5 years. Also, both direct and indirect comparisons demonstrated a more pronounced benefit with concurrent chemotherapy when compared to induction chemotherapy. The absolute benefit was $6.5 \%$ at 5 years. Cisplatin acts synergistically with radiation in the treatment of HNCA in the following ways- as a radiosensitizer by inhibiting potentially lethal and sublethal damage repair, as a hypoxic cell sensitizer, as a cell cycle inhibitor, by forming deoxyribonucleic acid adducts and as an inhibitor of angiogenesis (Marcu et al., 2003). The use of 3 weekly cisplatin at $100 \mathrm{mg} / \mathrm{m}^{2}$ concurrently with radiation is recommended now in the non-surgical management of locally advanced HNCA for organ preservation (Adelstein et al., 2003; Forastiere et al., 2003; Pignon et al., 2007). But only $60 \%$ of the patients actually remain fit enough to receive the desired 3 cycles of chemotherapy due to higher systemic and mucosal toxicities (Brizel et al., 2006). The non-compliance is even more in developing countries due to the limited resources (Dimri et al., 2013). Few studies have demonstrated comparable efficacy of weekly moderate dose cisplatin based chemoradiotherapy with less toxicity and better patient compliance, especially in developing countries with limited resources (Gupta et al., 2009; Dimri et al., 2013). The post-treatment response rates of tumors to concurrent chemoradiation with weekly cisplatin based regime was found to be similar to that reported in literature (Dimri et al., 2013). They found 86\% and 89\% complete response in primary tumor site and lymph nodes respectively.

In the laryngeal preservation trial by Forastiere et al. (Forastiere et al., 2003), only $70 \%$ patients received the desired 3 cycles of high dose cisplatin during radiation. Also Grade III or IV pharyngitis, haematological toxicity, emesis and nephrotoxicity were seen in $78 \%, 47 \%, 20 \%$ and $4 \%$ of the study patients respectively. Whereas, a HNCA study (Dimri et al., 2013) from India with weekly 35 $\mathrm{mg} / \mathrm{m}^{2}$ cisplatin based chemoradiation demonstrated acute Grade III or IV mucositis, emesis, anemia and leukopenia in $67 \%, 3 \%, 0.5 \%$ and $0.5 \%$ patients respectively. Another study (Gupta et al., 2009) demonstrated acute Grade III or IV mucositis and dermatitis in only $29 \%$ and $35 \%$ of the study patients respectively. Similarly, in the present study acute Grade III or IV mucositis, dermatitis, emesis, anemia and leukopenia were seen in $47.7 \%, 35.9 \%$, $6.6 \%, 1.4 \%$ and $5.9 \%$ study patients respectively. Even though most of the patients were from rural background and lacked proper nutrition, the high grade toxicities were quite comparable to other regional studies. Another study (Geeta et al., 2006) with $40 \mathrm{mg} / \mathrm{m}^{2}$ cisplatin based chemoradiotherapy demonstrated an overall treatment compliance of $65 \%$, significant hematologic toxicity of around $20 \%$ and treatment related hospital admissions of approximately $30 \%$.

In conclusion, the treatment of HNCA with $40 \mathrm{mg} / \mathrm{m}^{2}$ weekly cisplatin based chemoradiation is an effective and less toxic regime. It can be especially used in developing nations with limited resources, where intensive in-patient nursing care throughout the period of chemoradiation is not possible. The patient compliance also improves, thereby curtailing treatment breaks and improving tumor control.A long-term follow up randomized controlled trial should be undertaken in our setting to further estimate the efficacy of this regime when compared to the 3 weekly cisplatin based chemoradiation.

\section{References}

Adelstein DJ, Li Y, Adams GL, et al (2003). An Intergroup phase III comparison of standard radiation therapy and two schedules of concurrent chemo-radiotherapy in patients with unresectable squamous cell head and neck cancer. $J$ Clin Oncol, 21, 92-8.

Baykara M, Buyukberber S, Ozturk B, et al (2013). Efficacy and safety of concomitant chemoradiotherapy with cisplatin and docetaxel in patients with locally advanced squamous cell head and neck cancers. Asian Pac J Cancer Prev, 14, 2557-61.

Brizel DM, Esclamado R (2006). Concurrent chemoradiotherapy for locally advanced, nonmetastatic, squamous carcinoma of the head and neck: consensus, controversy, and conundrum. J Clin Oncol, 24, 2612-17.

Browman GP, Hodson DI, Mackenzie RG, et al (2001). Cancer care ontario practice guideline initiative head and neck cancer disease site group: choosing a concomitant chemotherapy and radiotherapy regimen for squamous cell 
Concurrent Chemoradiation with Weekly Cisplatin for Head and Neck Cancers: an Institutional Study of Toxicity and Response head and neck cancer: a systematic review of the published literature with subgroup analysis. Head Neck, 23, 579-89.

Chaturvedi P (2009). Head and neck surgery. J Can Res Ther, 5,143 .

Cox JD, Stetz J, Pajak TF (1995). Toxicity criteria of the radiation therapy oncology group (RTOG) and the European organization for research and treatment of cancer (EORTC). Int J Radiat Oncol Biol Phys, 31, 1341-6.

Dimri K, Pandey AK, Trehan R, et al (2013). Conventional radiotherapy with concurrent weekly cisplatin in locally advanced head and neck cancers of squamous cell origin- a single institution experience. Asian Pac J Cancer Prev, 14, 6883-88.

Fan KY, Gogineni H, Zaboli D, et al (2012). Comparison of acute toxicities in two primary chemoradiation regimens in the treatment of advanced head and neck squamous cell carcinoma. Ann Surg Oncol, 19, 1980-7.

Forastiere AA, Goepfert H, Maor M, et al (2003). Concurrent chemotherapy and radiotherapy for organ preservation in advanced laryngeal cancer. $N$ Engl J Med, 349, 2091-98.

Geeta SN, Padmanabhan TK, Samuel J, et al (2006). Comparison of acute toxicities of two chemotherapy schedules for head and neck cancers. J Cancer Res Ther, 2, 100-4.

Gupta T, Agarwal JP, Ghosh-Laskar S, et al (2009). Radical radiotherapy with concurrent weekly cisplatin in locoregionally advanced squamous cell carcinoma of the head and neck: a single-institution experience. Head Neck Oncol, $1,17$.

Lasrado S, Moras K, Pinto GJO, et al (2014). Role of concomitant chemoradiation in locally advanced head and neck cancers. Asian Pac J Cancer Prev, 15, 4147-52.

Marcu L, van Doorn T, Olver I (2003). Cisplatin and radiotherapy in the treatment of locally advanced head and neck cancer. Acta Oncol, 42, 315-25.

Mishra A, Meherotra R (2014). Head and neck cancer: Global burden and regional trends in India. Asian Pac J Cancer Prev, 15, 537-50.

Pandey KC, Revannasiddaiah S, Pant NK, et al (2014). Stagewise presentation of non-metastatic head and neck cancer: an analysis of patients from the Kumaon hills of India. Asian Pac J Cancer Prev, 15, 4957-61.

Pignon JP, Maitre AL, Bourhis J (2007). Meta-analyses of chemotherapy in head and neck cancer (MACH-NC): An update. Int J Radiat Oncol Biol Phys, 69, 112-4.

Pignon JP, Bourhis J, Domenge C, et al (2000). Chemotherapy added to locoregional treatment for head and neck squamous cell carcinoma: three meta-analyses of updated individual data. Lancet, 355, 949-55.

Pignon JP, Baujat B, Bourhis J (2005). Individual patient data meta-analysesin head and neck carcinoma: What have we learnt? Cancer Radiother, 9, 31-6.

Pignon JP, le Maitre A, Maillard E, et al (2009). MACH-NC collaborative group. Meta-analysis of chemotherapy in head and neck cancer (MACH-NC): an update on 93 randomised trials and 17,346 patients. Radiother Oncol, 92, 4-14.

Pruegsanusak K, Peeravut S, Leelamanit V, et al (2012). Survival and prognostic factors of different sites of head and neck cancer: an analysis from Thailand. Asian Pac J Cancer Prev, 13, 885-90. 